\title{
Breathing pattern adjustments during the first year following cervical spinal cord injury
}

\author{
B Loveridge B PT PhD,${ }^{1} \mathrm{R}$ Sanii PhD, ${ }^{1} \mathrm{H}$ I Dubo MD FRCPC ${ }^{2}$ \\ Spinal Cord Research Centre, University of Manitoba, ${ }^{1}$ School of Medical Rehabilitation, \\ Faculty of Medicine, ${ }^{2}$ Department of Medicine, Section of Rehabilitation Medicine, \\ University of Manitoba, 770 Bannatyne Avenue, Winnipeg, Manitoba R3E OW3, \\ Canada.
}

The alterations in lung function and breathing pattern were examined in 6 quadriplegics at 3, 6 and $>12$ months post injury, and were compared to 6 able bodied controls. Subjects were studied in both the seated and supine positions. Functional residual capacity (FRC), forced vital capacity (FVC), inspiratory capacity (IC), and maximum mouth pressure (Pimax) at FRC were measured. Total lung capacity (TLC) and residual volume (RV) were calculated. Resting breathing pattern was assessed for 20 minutes from a spirogram derived from summed rib cage and abdominal strain gauge signals. At 3 months in quadriplegics, TLC was reduced $(p<0.05)$, RV increased $(p<0.01)$ and FRC was normal in sitting; in supine, only TLC was reduced $(p<0.05)$; Pimax was decreased $(p<0.01)$ in both positions in quadriplegics at 3 months, but increased over the first year in the seated position $(p<0.01)$. There were no alterations in breathing pattern at any time interval in quadriplegics in supine. In contrast, at 3 months post injury in sitting, expiratory time (Te) was shortened $(p<0.05)$, tidal volume $(\mathrm{Vt})$ was decreased, and heart rate elevated as compared to controls $(p<0.05)$. Inspiratory time $(\mathrm{Ti})$ was not significantly shortened at 3 months in quadriplegics, but a lengthening of $\mathrm{Ti}$ occurred between 3 and 6 months $(p<0.025)$ resulting in increased $\mathrm{Vt}$, and heart rate decreased to normal. Vt/Ti was reduced, and did not alter with time. The lengthening of $\mathrm{Ti} /$ Ttot observed in supine in control subjects $(p<0.025)$, was not observed in quadriplegics. Quadriplegics sighed as frequently in supine as did controls at all stages post injury, whereas they decreased sighing frequency in sitting at 3 and 6 months post injury $(p<0.05)$. The improvement in resting breathing pattern observed in quadriplegics in sitting with time, may be due to increased accessory muscle function, improved chest wall stability and thoracoabdominal coupling, or a combination of these factors. It is also possible that the alterations in breathing pattern were a response to cardiovascular adjustments occurring in the same time frame. Quadriplegics retain the sigh reflex, but do not take as many big breaths in sitting as they do in supine, probably due to the increased work of breathing in the seated posture.

Key words: spinal cord injury; quadriplegia; lung function; lung mechanics; ventilation.

\section{Introduction}

Part of a comprehensive rehabilitation program with quadriplegic patients is directed at improving respiratory function. To evaluate the effectiveness of interventions designed to maximize breathing, it is important to have a clear understanding of the changes in lung function and breathing pattern with time post injury; and the effect position changes have on these parameters.

Alterations in lung mechanics with quadriplegics in both acute and chronic stages, and alterations with changes in position have been extensively investigated. ${ }^{1-9}$ It has 
been clearly demonstrated that forced vital capacity (FVC), inspiratory capacity (IC), and maximum inspiratory mouth pressure (Pimax) improve with time following cervical cord injury. ${ }^{8,10-12}$

There is less information on the changes in breathing pattern that occur with time; or the effects of alterations in posture on breathing pattern in quadriplegia. Earlier studies have assessed breathing pattern by measurement of tidal volume $(\mathrm{Vt})$ and frequency $(\mathrm{F}) .{ }^{13-15}$ The results are conflicting. It has been suggested that quadriplegics breathe shallowly, ${ }^{13}$ and that frequency is elevated in conjunction with a decreased Vt. ${ }^{16}$ Other authors have reported that tidal volume is preserved, and frequency is normal. ${ }^{14,15}$

Many studies have included patients at various stages of their recovery, or have compared different groups of patients. This study was designed to investigate prospectively the temporal changes in lung function and breathing pattern in both sitting and supine postures in quadriplegics following cervical cord injury; and to compare this data with an able bodied control group. Such a comprehensive profile in the same patients would provide a better baseline from which future evaluation of the benefits of respiratory rehabilitation techniques could be considered.

\section{Methods}

Six acute traumatic cervical cord injury male patients $(\mathrm{C} 5-\mathrm{C} 8)$, with a mean age of 30 years \pm 11 year, and with complete motor loss below the level of their lesion were recruited from the inpatient spinal cord injury unit at the rehabilitation centre. They were studied at 3 months, 6 months and $>12$ months post injury (12-18 months post injury), in both the seated and supine positions. The order of the position of study was randomly determined. No quadriplegic subjects wore abdominal support devices. One patient was discharged to a distant rural home before we were able to study him at the 6 month interval in the supine position, and one subject did not complete the supine study at the $>12$ months interval. The data therefore represent 6 quad- riplegic subjects for all seated measurements, but only 5 quadriplegic subjects for the supine data at both 6 months, and $>12$ months. Six age (30 years \pm 10 years), and sex matched able bodied controls were also studied in both the seated and supine positions for comparison. Informed consent was obtained from all subjects.

Functional residual capacity (FRC) was measured using the nitrogen washout technique. Forced vital capacity (FVC), inspiratory capacity (IC), and forced expiratory volume in one second (FEV1.0) were measured with a portable spirometer (Spiromate model AS300). This device provided a printed display of the flow volume loop, and a 3 breath average display for establishment of FRC and the measurement of IC. The accuracy of the volume measurements with this portable spirometer were checked with a calibrating syringe and a less than $3 \%$ error in volume measurements was recorded. Total lung capacity (TLC), and residual volume (RV) were calculated. Maximum inspiratory mouth pressure (Pimax) was measured at FRC using a comparable technique to that described by Black and Hyatt. ${ }^{17} \mathrm{~A}$ minimum of 6 measurements were made with each subject at each test interval. If these measurements were within $5 \%$ of each other then the average of the 3 highest measurements was recorded as Pimax. If greater variability was observed in the Pimax measurements repeated measurements were made following a brief rest.

Ventilation and resting breathing pattern were assessed using mercury in rubber strain gauges. The details of this technique have been previously published. ${ }^{16,18}$ The strain gauges were calibrated separately for each position of study and the calibration factors derived in this position were checked at the end of each data collection period to ensure accuracy of this technique. Briefly, 20 minutes of resting breathing pattern were recorded in each position, prior to other ventilatory tests being conducted. Two strain gauges were applied to the chest wall; one around the ribcage one inch below the nipple line, and one to the abdomen, midway between the xiphoid and the umbilicus. During calibration, the subjects wore 
nose clips and breathed through a pneumotachygraph for a period of one minute. Multiple linear regression analysis was used to compare the known volume source with the summed ribcage and abdominal strain gauge signals. The stability of the calibration factors was verified at the end of each study, prior to a change in position, when the subject again breathed through the pneumotachygraph for one minute, and the best fit equation used in calibration was applied to the data. Calibration, and verifications were accepted with strain gauge predicted volumes varying less than $10 \%$ from pneumotachygraph measured volumes. A single lead electrocardiogram (modified V5 position) was employed to measure resting heart rate, and to ensure that the subject remained in a steady state throughout the 20 minute recording period. Subjects watched a videotape to distract them from the monitoring devices. As well, subjects were indirectly observed throughout the recording of strain gauge signals, and movement artifacts were identified on the chart recording.

The best fit calibration equation was then used to recreate a spirogram from the summed RC and ABD signals. The spirogram was analyzed with a computer assisted program. Movement artifacts were removed from the computer file prior to the analysis of the timing components of the spirogram. The peak (end of inspiration), and trough (beginning of the next inspiration), were identified manually on the computer generated spirogram with the assistance of an $x-y$ plotter. These values were stored and used to calculate inspiratory time $(\mathrm{Ti})$, expiratory time $(\mathrm{Te})$, and tidal volume $(\mathrm{Vt})$. The remaining timing components were derived from these values. The mean, standard deviation, standard error of the estimate, and coefficient of variation were calculated for each timing variable. Breaths greater than 2 and 3 times mean tidal volume were determined from a computer histogram program.

The data was analyzed using paired t-tests to assess changes between 3 months and 6 months, and between 6 months and $>12$ months for each variable, in each position. The data was also subjected to analysis of variance to compare 3,6 and $>12$ months values for each position. Tukey's test was then applied to determine significant differences.

\section{Results}

The pulmonary function data for controls and quadriplegic subjects at 3,6 , and $>12$ months post injury, in both the seated and supine positions are summarized in Figure 1. The decrease in FRC observed in controls on assuming the supine position was similarly observed in quadriplegics $(p<0.005)$. TLC was decreased at 3 months $(p<0.05)$ in sitting and supine in quadriplegics as compared to able bodied subjects, and remained unchanged during the first year. Small but significant decreases in TLC were observed when quadriplegics altered posture from sitting to supine at both 3 months $(p<0.05)$, and $>12$ months post injury $(p<0.01)$. In contrast, TLC did not alter with position change in controls. RV was significantly elevated in quadriplegics in the seated position at 3 months $(p<0.01)$, and remained elevated at $>12$ months post injury. In contrast, there was no significant differences in $\mathrm{RV}$ between quadriplegics and controls in supine. Large inter-subject variability in supine RV measurements were observed in the quadriplegic group (Fig 1).

FVC, IC, Pimax. were reduced at all temporal stages post injury in both sitting and supine with quadriplegics as compared to controls $(p<0.01)$. All 3 variables increased significantly in sitting between 3 and 6 months post injury $(p<0.01)$. In the seated position, FVC, and PiMax increased further at $>12$ months post injury $(p<0.05)$, while IC did not improve beyond 6 months. In supine, FVC increased between 3 and 6 months $(p<0.005)$, but Pimax and IC did not increase beyond 3 months.

Mean resting heart rates have been included in Table 1. Heart rate was significantly elevated in quadriplegics in sitting at 3 months post injury $(p<0.01)$. Mean heart rate of the quadriplegic group in the seated posture decreased between 3 and 6 months $(p<0.005)$. In contrast, there were no differences in resting heart rate between 


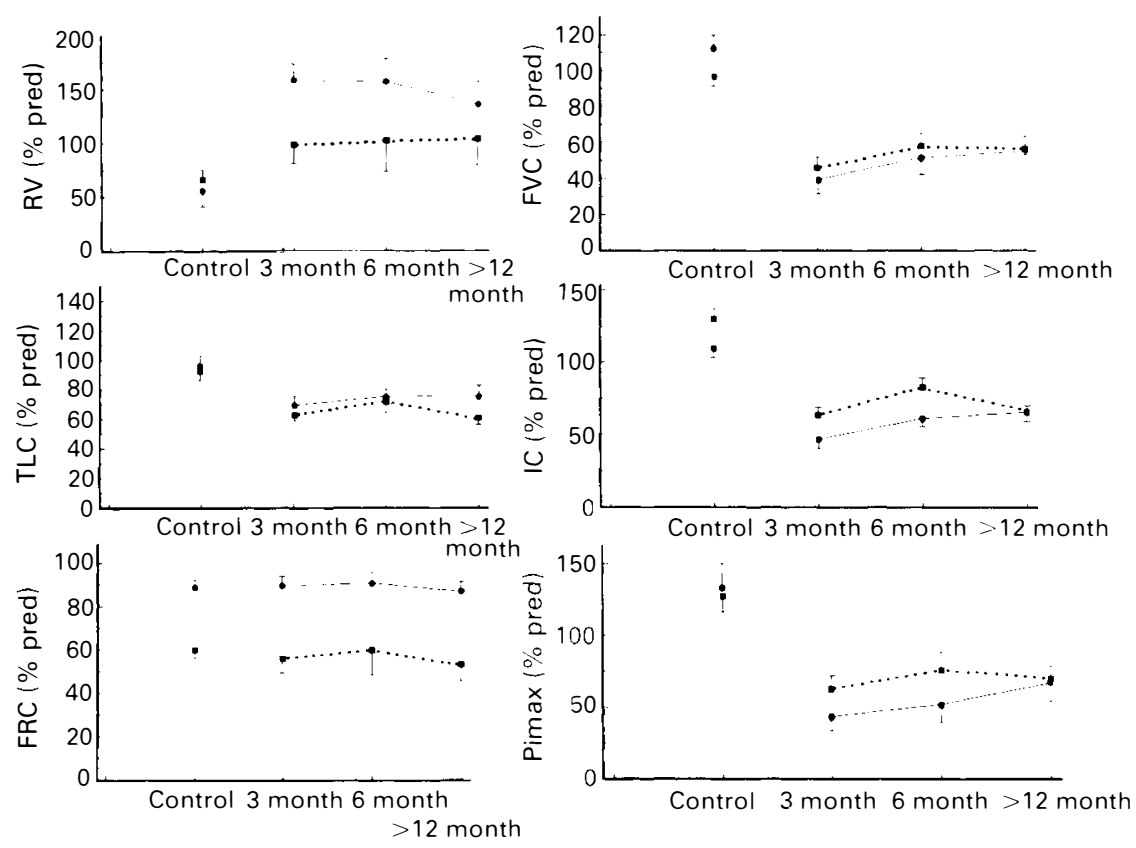

Figure 1 Comparison of the changes in lung function in both the seated $(-)$ and supine (.......) postures, between quadriplegics at 3, 6 and $>12$ months post injury, and normal controls. Data represents mean \% predicted values and the bars represent the standard error of the estimate.

quadriplegics and controls in supine at any time interval.

Resting breathing pattern was altered in the seated position in quadriplegics early post injury as compared to controls (Table 1). In contrast, there were no significant differences in any of the timing components of breathing between quadriplegics, at any stage post injury, and able bodied controls in the supine position.

In the seated position, Te was shortened $(p<0.05)$, and therefore frequency increased $(p<0.05)$, at 3 months post injury in quadriplegics as compared to controls. Te lengthened between 3 and 6 months in sitting $(p<0.005)$, accounting for the decreased frequency observed in quadriplegics at 6 months $(p<0.005)$.

Te also lengthened with a change in position from sitting to supine at 3 months post injury $(p<0.01)$, resulting in a lower frequency of breathing in supine $(p<0.01)$. No alterations in $\mathrm{Te}$ were observed with position changes in quadriplegics beyond the 3 month interval.
The changes in Ti were less consistent. Ti was shortened to less than 1 second in 3 of the 6 quadriplegics at 3 months post injury, with a corresponding large decrease in Vt. The other 3 subjects had values for $\mathrm{Ti}$ and Vt which overlapped with those of normal individuals, resulting in no significant decrease in $\mathrm{Ti}$ or $\mathrm{Vt}$ being observed for the quadriplegic group as compared to controls. There was no correlation between lesion level and the decreased $\mathrm{Ti}$ observed. $\mathrm{Ti}$ increased significantly between 3 and 6 months post injury in the seated posture in all quadriplegics regardless of the initial $\mathrm{Ti}$ values observed at 3 months $(p<0.025)$. Ti also lengthened in the supine posture as compared to sitting at 3 months $(p<0.05)$.

Tidal volume remained unchanged with time post injury in both positions in the quadriplegic subjects. No significant differences in $\mathrm{Vt}$ were observed with position change in either the quadriplegics or controls. Mean minute ventilation (Ve) was maintained in all quadriplegics at all time intervals, in both sitting and supine postures 
Table I Breathing pattern in quadriplegics and able bodied subjects in sitting and supine

\begin{tabular}{|c|c|c|c|c|c|c|c|c|}
\hline & \multicolumn{2}{|c|}{ Controls } & \multicolumn{6}{|c|}{ Quadriplegics } \\
\hline & \multirow[b]{2}{*}{ Sit } & \multirow[b]{2}{*}{ Sup } & \multicolumn{2}{|c|}{3 months } & \multicolumn{2}{|c|}{6 months } & \multicolumn{2}{|c|}{$>12$ months } \\
\hline & & & Sit & Sup & Sit & Sup & Sit & Sup \\
\hline $\begin{array}{l}\mathrm{Ti} \\
(\mathrm{sec})\end{array}$ & $\begin{array}{l}1.33 \\
0.12\end{array}$ & $\begin{array}{l}1.42 \\
0.09\end{array}$ & $\begin{array}{l}1.16 \\
0.11\end{array}$ & $\begin{array}{l}1.44^{*} \\
0.09\end{array}$ & $\begin{array}{l}1.38 \\
0.13\end{array}$ & $\begin{array}{l}1.61 \\
0.12\end{array}$ & $\begin{array}{l}1.45 \\
0.16\end{array}$ & $\begin{array}{l}1.56 \\
0.13\end{array}$ \\
\hline $\begin{array}{l}\mathrm{Te} \\
(\mathrm{sec})\end{array}$ & $\begin{array}{l}2.63 \\
0.24\end{array}$ & $\begin{array}{l}2.31 \\
0.25\end{array}$ & $\begin{array}{l}1.98+ \\
0.19\end{array}$ & $\begin{array}{l}2.57^{*} \\
0.19\end{array}$ & $\begin{array}{l}2.39 \\
0.27\end{array}$ & $\begin{array}{l}2.48 \\
0.27\end{array}$ & $\begin{array}{l}2.58 \\
0.33\end{array}$ & $\begin{array}{l}2.70 \\
0.40\end{array}$ \\
\hline $\begin{array}{l}\mathrm{Vt} \\
(\mathrm{ml})\end{array}$ & $\begin{array}{r}419 \\
46\end{array}$ & $\begin{array}{r}325 \\
25\end{array}$ & $\begin{array}{r}296 \\
38\end{array}$ & $\begin{array}{r}315 \\
26\end{array}$ & $\begin{array}{r}326 \\
21\end{array}$ & $\begin{array}{r}297 \\
17\end{array}$ & $\begin{array}{r}344 \\
20\end{array}$ & $\begin{array}{r}304 \\
34\end{array}$ \\
\hline Freq & $\begin{array}{r}16 \\
1\end{array}$ & $\begin{array}{r}17 \\
1\end{array}$ & $\begin{array}{c}20+ \\
2\end{array}$ & $\begin{array}{c}15^{*} \\
1\end{array}$ & $\begin{array}{r}17 \\
2\end{array}$ & $\begin{array}{r}15 \\
1\end{array}$ & $\begin{array}{r}16 \\
2\end{array}$ & $\begin{array}{r}16 \\
2\end{array}$ \\
\hline $\begin{array}{l}\mathrm{Ve} \\
\mathrm{L} / \mathrm{min}\end{array}$ & $\begin{array}{l}6.57 \\
0.62\end{array}$ & $\begin{array}{l}5.43 \\
0.60\end{array}$ & $\begin{array}{l}5.71 \\
0.49\end{array}$ & $\begin{array}{l}4.74 * \\
0.29\end{array}$ & $\begin{array}{l}4.40 \\
0.37\end{array}$ & $\begin{array}{l}5.36 \\
0.30\end{array}$ & $\begin{array}{l}5.48 \\
0.61\end{array}$ & $\begin{array}{l}4.73 \\
0.86\end{array}$ \\
\hline $\mathrm{Vt} / \mathrm{Ti}$ & $\begin{array}{l}.325 \\
.029\end{array}$ & $\begin{array}{l}.232 \\
.017\end{array}$ & $\begin{array}{l}.261 \\
.013\end{array}$ & $\begin{array}{l}.220 * \\
.019\end{array}$ & $\begin{array}{l}.245 \\
.016\end{array}$ & $\begin{array}{l}.185 \\
.014\end{array}$ & $\begin{array}{l}.252 \\
.027\end{array}$ & $\begin{array}{l}.203 \\
.024\end{array}$ \\
\hline $\mathrm{Ti} /$ Ttot & $\begin{array}{l}.344 \\
.011\end{array}$ & $\begin{array}{l}.389^{*} \\
.016\end{array}$ & $\begin{array}{l}.372 \\
.018\end{array}$ & $\begin{array}{l}.364 \\
.012\end{array}$ & $\begin{array}{l}.371 \\
.009\end{array}$ & $\begin{array}{l}.392 \\
.014\end{array}$ & $\begin{array}{l}.365 \\
.013\end{array}$ & $\begin{array}{l}.383 \\
.025\end{array}$ \\
\hline RHR & $\begin{array}{r}70 \\
2\end{array}$ & $\begin{array}{r}63 \\
1\end{array}$ & $\begin{array}{c}93+* \\
2\end{array}$ & $\begin{array}{r}73 \\
3\end{array}$ & $\begin{array}{r}75 \\
2\end{array}$ & $\begin{array}{r}69 \\
2\end{array}$ & $\begin{array}{r}67 \\
2\end{array}$ & $\begin{array}{r}55 \\
2\end{array}$ \\
\hline
\end{tabular}

Values represent means and standard error of the estimate; seated measurements (Sit); supine measurements (Sup); resting heart rate (RHR)

* Sitting values significantly different from supine values for that time interval $(p<0.05)$

+ Values significantly different from control value in the same position $(p<0.05)$

as compared to controls. There was a significant increase in Ve in sitting as compared to supine at 3 months post injury $(p<0.025)$. This was due primarily to the increased frequency observed in the seated posture at this time.

There were no significant differences in $\mathrm{Vt} / \mathrm{Ti}$ at any time interval, between quadriplegics and controls in sitting, or supine postures. At 3 months, $\mathrm{Vt} / \mathrm{Ti}$ increased in sitting as compared to supine in the quadriplegic group $(p<0.05)$.

$\mathrm{Ti} /$ Ttot lengthened in controls in the supine posture as compared to sitting $(p<0.025)$, whereas in quadriplegics no changes in $\mathrm{Ti} / \mathrm{T}$ tot were observed with position change or passage of time. Variability of breathing was assessed by comparing the coefficients of variation for each timing component of the spirogram between the seated and supine postures, and between the quadriplegics and controls at all time intervals. No differences in variability were observed.

None of the alterations in breathing pattern observed between sitting and supine at 3 months post injury with the quadriplegic subjects were observed at 6 months, or $>12$ months post injury. Figure 2 compares the mean alterations in the resting spirogram in the seated position between quadriplegics at 3,6 , and $>12$ months and controls.

Sighing frequency is summarized in Figure 3. In the seated position, all controls had breaths $>2 \mathrm{x}$ mean Vt during the 20 minute study (range of 1-7 breaths each), and 2 subjects had breaths $>3 \mathrm{x}$ mean $\mathrm{Vt}$ (range 2-3 breaths). In contrast, at 3 months post injury only the $\mathrm{C} 8$ quadriplegic had any breaths $>2 \mathrm{x}$ or $>3 \mathrm{x}$ mean $\mathrm{Vt}$ in sitting, and this subject had only one breath $>3 \mathrm{x}$ mean Vt. Sighing frequency in quadriplegics was increased in supine as compared to sitting at both 3 , and 6 months post 


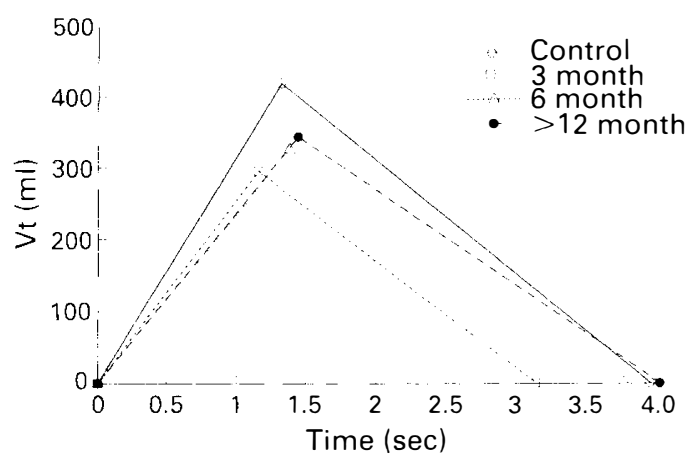

Figure 2 Comparison of the mean spirogram between controls and quads at 3,6, and $>12$ months post injury in the seated position.

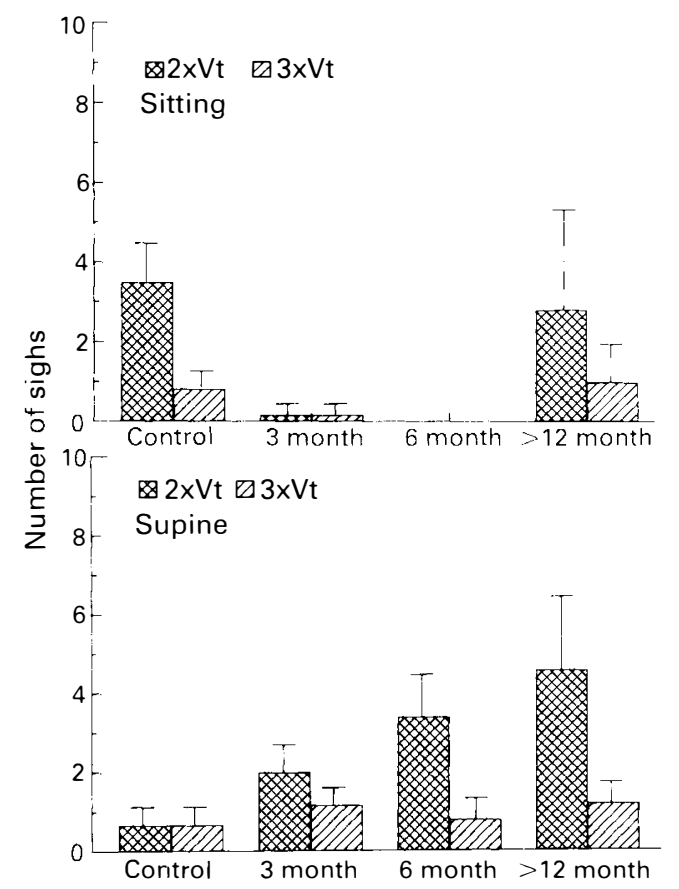

Figure 3 Comparison of the frequency of breaths $>2 \mathrm{x}$ mean $\mathrm{Vt}$, and $>3 \mathrm{x}$ mean $\mathrm{Vt}$ between quadriplegics and controls in both the seated and supine postures ( $20 \mathrm{~min}$ period).

injury $(p<0.05)$. In contrast, there were no differences in sighing frequency with position change in controls.

\section{Discussion}

The results indicate that the seated position imposes a greater stress on the cardiovascular and respiratory systems early post injury in quadriplegics, than is observed in the supine position. Breathing pattern adjustments are required to maintain minute ventilation in acute quadriplegics in sitting. With the passage of time, breathing pattern improved in the seated position, and the differences observed between the seated and supine postures in quadriplegics became insignificant. In contrast to the changes observed in sittting, breathing pattern in quadriplegics at all stages post injury in the supine posture was comparable to controls.

The lung volume changes resulting from paralysis of the intercostal, and abdominal muscles in cervical cord injured persons reported by previous investigators, $, 2,4,5,8,11,19,20$ are confirmed in this study.

It has been suggested that increased accessory respiratory muscle strength contributes to the increased IC and Pimax observed with time. ${ }^{8}$ However, if this were the only factor contributing to the increased Pimax, one would expect to observe similar increases in Pimax in supine. We observed no significant increases in Pimax in supine beyond 3 months post injury.

Improvement in pulmonary function with time post injury, has also been attributed to increased stability of the ribcage and abdominal wall due to the development of spasticity, ${ }^{9.11}$ as well as increased abdominal compliance, ${ }^{21}$ and improved thoraco-abdominal coupling with time..$^{9,21}$ Factors which improve thorax stabilization could also account for the increased Pimax observed in sitting. Quadriplegics may learn to utilize intact neck and shoulder girdle muscles to better mechanical advantage with time, resulting in better fixation of the thorax, and increased Pimax measurements in the seated posture.

The major alterations in the timing components of ventilation occurred between 3 and 6 months post injury in the seated posture (Table 1). In contrast, breathing pattern in the supine position remained comparable to able bodied controls at all temporal stages following cervical spinal cord injury.

$\mathrm{Vt} / \mathrm{Ti}$ was consistently lower in the seated position in quadriplegics at all stages post injury as compared to controls, although 
these differences were not significant with this small sample (Fig 2). Like other patients with restrictive lung disorders such as pulmonary fibrosis who increase $\mathrm{Vt} / \mathrm{Ti}$ above normal values of maintain $\mathrm{Vt},{ }^{22,23}$ quadriplegics appear to elevate $\mathrm{Vt} / \mathrm{Ti}$ in the seated position (Table 1). Vt/Ti was significantly elevated in sitting as compared to supine, at 3 months $(p<0.05)$. However, unlike able bodied subjects, ${ }^{24}$ or persons with other restrictive disorders, quadriplegics appear to be unable to increase $\mathrm{Vt} / \mathrm{Ti}$ sufficiently to maintain $\mathrm{Vt}$. This is not surprising, given the added mechanical disadvantage for the ventilatory muscles in the seated position due to paralysis of the intercostal and abdominal muscles, ${ }^{13}$ and the effects of gravity. ${ }^{9}$ Thoraco-abdominal distortion, which greatly adds to the work of breathing in quadriplegics, is also particularly apparent early post injury. ${ }^{7}$

It has been observed that respiratory muscle weakness alone does not result in a decreased $\mathrm{Vt} / \mathrm{Ti}^{25}$ Diminished sensory feedback in quadriplegics due to paralysis of most of the extra-diaphragmatic muscles has been suggested as a reason for the smaller observed increase in diaphragmatic activation in the seated posture in quadriplegics as compared to normal subjects. ${ }^{26}$

FRC in quadriplegics is comparable to that observed in able bodied controls at all stages of recovery in sitting and supine, so that alterations in resting diaphragm length are less likely to account for the adjustments in breathing pattern observed. ${ }^{8}$

We were unable to identify any factor which may account for the fact that some quadriplegics shortened $\mathrm{Ti}$ and, coupled with an inability to markedly increase $\mathrm{Vt} / \mathrm{Ti}$, adopted a very rapid, shallow breathing pattern early post injury. Other quadriplegics maintained a relatively normal $\mathrm{Ti}$ and, therefore, $\mathrm{Vt}$. There were no significant correlations between the timing components of the spirogram, and any of the other lung function parameters that we measured. Clinically all subjects had complete motor and sensory loss below the lesion levels, but it is possible that a more extensive electrophysiological evaluation of sensory impairment may have uncovered differences between the quadriplegics. There may also have been other mechanical differences between our quadriplegic subjects which we did not measure. Earlier stabilization of the chest wall, and improved thoraco-abdominal coupling post injury may be apparent in some quadriplegics, and account for the discrepancies in breathing pattern observed.

However, it is also possible that the rapid shallow breathing pattern observed in the seated posture at 3 months post injury may originate, at least in part, from receptor inputs from the cardiovascular system. ${ }^{27,28}$ We observed a marked increase in resting heart rate in quadriplegics in the seated position at 3 months, as compared to supine. While we did not assess blood pressure during the study it has been well documented that postural hypotension is common in quadriplegics, and that blood pressure is lowered in the seated posture as compared to supine in quadriplegics. ${ }^{27,28}$ The observed postural hypotension in quadriplegics with tilting is accompanied by an elevated heart rate. ${ }^{28}$ Vena cava occlusion in supine dogs has been shown to increase frequency of breathing. ${ }^{29}$ As well, acute hypertension experiments with cats have demonstrated the effects of altered peripheral baroreceptor inputs on ventilatory control. ${ }^{30-32}$ A lengthening of Te, ${ }^{30}$ a drop in $\mathrm{Vt}$ and prolongation of $\mathrm{Ti}^{31}$ and $\mathrm{a}$ slowing of heart rate ${ }^{30}$ have been observed. These observations would support the hypothesis that the hypotension may have contributed to the alterations in the timing components of the spirogram observed in quadriplegics at 3 months post injury. We observed a decreased $\mathrm{Te}$ and a shortened or unchanged $\mathrm{Ti}$, and accompanying increased heart rate in quadriplegics at 3 months. Adaptation of the cardiovascular system with time post injury, probably accounts for the decreased heart rate observed by 6 months. This decreased heart rate response coincides with the improvement in timing of ventilation in the seated position. Such a hypothesis would also account for the fact that the alterations in breathing pattern observed in the seated posture at 3 months were not present in the supine posture where the cardiovascular effects in quadriplegia would be minimized.

The variability in $\mathrm{Ti}$ observed in sitting 
regardless of time post injury may account for the discrepancies between studies regarding the presence ${ }^{13,16,33}$ or absence ${ }^{14,15}$ of shallow breathing in quadriplegics. Three of 6 quadriplegics in this study had Ti's less than one second at 3 months post injury in the seated position, while the remaining 3 quadriplegics had $\mathrm{Ti}$ within normal ranges. We also observed $\mathrm{Ti}$ of less than one second in 2 of 14 chronic quadriplegics in sitting, in a previous investigation. ${ }^{33}$ Quadriplegics who maintain $\mathrm{Ti}$ appear to maintain a $\mathrm{Vt}$ within normal or low normal limits; those quadriplegics who shorten $\mathrm{Ti}$ as well as having a diminished $\mathrm{Vt} / \mathrm{Ti}$ do not appear to be able to maintain $\mathrm{Vt}$ in sitting. Te shortened in all quadriplegics at 3 months post injury and resulted in the increased frequency observed. Vt was lower and frequency higher in all quadriplegics at 3 months post injury, as compared to able bodied controls $(p<0.01)$. Regardless of the initial $\mathrm{Ti}, \mathrm{Ti}$ lengthened significantly between 3 and 6 months in all quads providing an increased Vt. This was accompanied by a lengthening of $\mathrm{Te}$, and $\mathrm{a}$ corresponding reduction in frequency of breathing. Minute ventilation, therefore, remained unchanged. There was a tendency towards a further slight increase in $\mathrm{Ti}$ between 6 months and $>12$ months (Fig 2). Within the first year, quadriplegics appear to lengthen $\mathrm{Ti}$ in sitting rather than increase mean inspiratory flow ( $\mathrm{Vt} / \mathrm{Ti})$ in an attempt to increase $\mathrm{Vt}$.

While Ti/Ttot in the quadriplegics was not significantly different from normals in this study, 2 quadriplegics had $\mathrm{Ti} /$ Ttot $>0.400$ while no normal control had a $\mathrm{Ti} /$ Ttot $>0.385$ in the seated posture. In an earlier larger study of chronic quadriplegics 8 of 14 subjects had Ti/Ttot in excess of $0.400 .{ }^{33}$ It has been suggested that prolonged $\mathrm{Ti} /$ Ttot may predispose the ventilatory muscles to fatigue. ${ }^{34}$ There is, however, no evidence that prolonged $\mathrm{Ti} /$ Ttot result in ventilatory muscle fatigue in quadriplegics. In support of the suggestion that inspiratory muscle impairment may account for a lengthening of $\mathrm{Ti} / \mathrm{Tt}$ tot is the observation that $\mathrm{Ti} / \mathrm{T}$ tot decreased significantly with increases in Pimax with quadriplegics. ${ }^{16}$ The increased $\mathrm{Ti} /$ Ttot in normal subjects in supine as compared to sitting was not observed in the quadriplegics at 3 months. ${ }^{26}$

It appears that quadriplegics retain the ability to sigh, and sigh as frequently as able bodied persons in the supine posture. A previous report, ${ }^{15}$ suggested that quadriplegics sighed less frequently than normal subjects. However, this study compared quadriplegics in the supine posture to normal subjects in sitting which may account for the differences between their results and ours. It appears that normal subjects sigh more frequently in sitting than in supine, while the reverse is true for quadriplegics (Fig 3). The decreased sighing frequency observed in quadriplegics in the seated position, particularly early post injury, may reflect the increased work of breathing required to distort the thorax during a large breath in that position. ${ }^{7,9}$ Quadriplegics have intact vagi which would rule out a lack of vagal afferents in initiating a sigh in the seated posture. ${ }^{15}$ Perhaps taking big breaths in sitting is simply too costly in terms of energy expenditure and therefore quadriplegics do not sigh as frequently or with breaths of as great amplitude in sitting. There appears to be an increase in the frequency of sighing in the seated posture with the passage of time (Fig 3 ).

\section{Conclusion}

Quadriplegics have significantly impaired ventilatory lung function, and altered breathing patterns in sitting early post injury. Although breathing pattern improves with time in the seated posture, many quadriplegics retain a more rapid, shallow breathing pattern in the chronic phase. ${ }^{16.33}$ Quadriplegics retain the ability to sigh, but sigh less frequently in the seated position during the first 6 months post injury.

Improvement in breathing pattern in sitting between 3 and 6 months post injury coincides with the decreased heart rate observed in the same time frame. Whether such alterations in breathing pattern are secondary to either acute or chronic hypotension, or due primarily to mechanical changes in the lungs and chest wall remains unclear. 


\section{Acknowledgement}

This study was supported by a grant from the

Manitoba Health Research Council.

\section{References}

1 Haas F, Pineda H, Axen K, Bresnahan C, Haas A (1978) Time related, posturally induced changes in pulmonary function in spinal cord injured man. Am Rev Respir Dis 117: 344.

2 Fugl-Meyer AR (1971) Effects of respiratory muscle paralysis in tetraplegic and paraplegic patients. Scand $J$ Rehab Med 3: 141-150.

3 Maloney FP (1979) Pulmonary function in quadriplegia: effects of a corset. Arch Phys Med Rehabil 60: 261-265.

4 Huldtgren A-C, Fugl-Meyer AR, Jonasson E, and Bake B (1980) Ventilatory dysfunction and respiratory rehabilitation in post-traumatic quadriplegia. Eur J Respir Dis 61: 347-356.

5 Estenne M, DeTroyer A (1987) Mechanism of the postural dependence of vital capacity in tetraplegic subjects. Am Rev Respir Dis 135: 367-371.

6 McCool FD, Brown R, Mayewski J, Hyde RW (1988) Effects of posture on stimulated ventilation in quadriplegia. Am Rev Respir Dis 138: 101-105.

7 Scanlon PD, Loring SH, Pichurko BM, McCool FD, Slutsky AS, Sarkarati M et al (1989) Respiratory mechanics in acute quadriplegia. Am Rev Respir Dis 139: 615-620.

8 Pichurko B, McCool FD, Scanlo P, Loring S, Slutsky A, Rossier A, Sarkarati M et al (1985) Factors related to respiratory muscle function recovery following acute quadriplegia. Am Rev Respir Dis 131: A337.

9 DeTroyer A, Heilporn A (1980) Respiratory mechanics in quadriplegia. The respiratory function of the intercostal muscles. Am Rev Respir Dis 122: 591-600.

10 Ohry A, Molho M, Rozin R (1975) Alterations of pulmonary function in spinal cord injured patients. Paraplegia 13: 101-108.

11 McMichan JC, Michel L, Westbrook PR (1980) Pulmonary dysfunction following traumatic quadriplegia. JAMA 243(6): 528-531.

12 Ledsome JR, Sharp JM (1981) Pulmonary function in acute cervical cord injury. Am Rev Respir Dis 124: 41-44.

13 Bergofsky EH (1964) Mechanism for respiratory insufficiency after cervical cord injury. Ann Intern Med 61(3): 435-477.

14 Stone DJ, Keltz H (1963) The effect of respiratory muscle dysfunction on pulmonary function. Am Rev Respir Dis 88: 621-629.

15 McKinley AC, Auchincloss JH, Gilbert R, Nicholas JJ (1969) Pulmonary function, ventilatory control, and respiratory complications in quadriplegic subjects. Am Rev Respir Dis 100: 526-532.

16 Loveridge B, Badour M, Dubo H (1989) Ventilatory muscle endurance training in quadriplegia: effects on breathing pattern. Paraplegia 27: 329-339.

17 Black LF, Hyatt RE (1971) Maximal static respiratory pressures in generalized neuromuscular disease. Am Rev Respir Dis 103: 641-650.

18 Loveridge B, West P, Anthonisen NR, Kryger MH (1983) Single-position calibration of the respiratory inductance plethysmograph. J Appl Physiol 55(3): 1031-1034.

19 Fugl-Meyer AR, Grimby G (1971) Ventilatory function in tetraplegic patients. Scand J Rehab Med 3: 151-160.

20 McCool FD, Pichurko BM, Slutsky AS, Sarkarati M, Rossier A, Brown R (1986) Changes in lung volume and configuration with abdominal binding in quadriplegia. J Appl Physiol 60(4): 1198-1202.

21 Estenne M, De Troyer A (1986) The effects of tetraplegia on chest wall statics. Am Rev Resp Dis 134: 121-124.

22 Tobin MJ, Chadha TS, Jenouri G, Birch S, Gazeroglu HB, Sackner MA (1983) Breathing patterns: diseased subjects. Chest 84:(3): 286-294.

23 Savoy J, Dhingra S, Anthonisen NR (1981) Role of vagal airway reflexes in control of ventilation in pulmonary fibrosis. Clin Sci Molecular Med 61: 781-784.

24 Weissman C, Abraham B, Askanazi J, Milic-Emili J, Hyman AI, Kinney JM (1982) Effect of posture on the ventilatory response to CO2. J Appl Physiol 53(3): 761-765.

25 Newsom Davis J, Stagg D, Loh L, Casson M (1976) The effects of respiratory muscle weakness on some features of the breathing pattern. Clin Sci 50: 10P-11P.

26 Green M, Mead J, Sears TA (1978) Muscle activity during wall restriction and positive pressure breathing in man. Respir Physiol 35: 283-300.

27 Kooner JS, Frankel HL, Mirando N, Peart WS, Mathias CJ (1988) Haemodynamic, hormonal and urinary responses to postural change in tetraplegic and paraplegic men. Paraplegia 26: 233-237.

28 Mathias CJ, Christensen NJ, Corbett JL, Frankel HL, Goodwin TJ, Peart WS (1975) Plasma catecholamines, plasma renin activity and plasma aldosterone in tetraplegic man, horizontal and tilted. Clin Sci Molecular Med 49: 291-299. 
29 Baer RE, Leeman M, Farkas GA, Naeije R, DeTroyer A (1987) The increased expiratory muscle use in upright dogs:role of cardiovascular receptors. Resp Physiol 70: 359-368.

30 Trelease RB, Sieck GC, Marks JD, Harper RM (1985) Respiratory inhibition induced by transient hypertension during sleep in unrestrained cats. Exper Neurol 90: 173-186.

31 Grunstein MM, Derenne JP, Milic-Emili J (1975) Control of depth and frequency of breathing during baroreceptor stimulation in cats. J Appl Physiol 39(3): 395-404.

32 Bishop B (1974) Carotid baroreceptor modulation of diaphragm and abdominal muscle activity in the cat. $J$ Appl Physiol 36(1): 12-19.

33 Loveridge B, Dubo H (1990) Breathing pattern in chronic quadriplegia. Arch Phys Med Rehabil 71: 495-499.

34 Bellemare F, Grassino A (1983) Force reserve of the diaphragm in patients with chronic obstructive pulmonary disease. J Appl Physiol 55: 8-15. 